\section{Influence of Seed Hydration on Seedling Performance}

\author{
A.G. Taylor', J. Prusinski', \\ H.J. Hill ${ }^{3}$, and \\ M.D. Dickson ${ }^{4}$
}

Additional index words. seedling emergence forces, imbibitional chilling injury, semi-hard seed, seed coating, priming, conditioning

Summary. Water is pervasively involved in the life cycle of seeds. Water in the environment, either as a vapor or liquid, directly affects seed moisture status. This article is devoted to the study of seed moisture status in postharvest events. Two topics are discussed: imbibitional chilling injury and upgrading of primed seeds. Imbibitional chilling injury is a physiological disorder that occurs in largeseeded legumes as well as other important agronomic seeds. Imbibitional chilling injury has been shown to reduce the survival rate of seedlings. Surviving seedlings have less emergence force per seedling and require a longer period to generate maximum force. Rapid hydration has been shown to induce injury at a particular seed moisture level. Methods of regulating the hydration rate were explored to alleviate chilling injury in snap beans (Phaseolus vulgaris L.) Plant breeding lines with the semihard seed

Department of Horticultural Sciences, New York State Agricultural Experiment Station, Cornell University, Geneva, NY 14456.

This work was partially supported from grants from the New York State Science and Technology Foundation, New York State Snap Bean Association, Royal Sluis and Harris-Moran Seed Co.

'Associate Professor.

${ }^{2}$ Former Visiting Scientist.

${ }^{3}$ Former Postdoctoral Research Associate.

${ }^{4}$ Professor. characteristic delayed the onset of imbibition when the initial moisture level was low (8\%). Coating seeds with polymeric films to complement the permeable testa retarded the imbibition rates. Both approaches alleviated chilling injury and improved seedling establishment under stressful conditions. Seed priming is a technique for elevation of seed moisture content before sowing. Primed seeds generally emerge more quickly than nonprimed seeds, especially under stressful environmental conditions. An additional merit of this technique is that it gives access to seeds with elevated moisture content. Various approaches may be employed to condition seeds after priming, but before redesiccation.

Discarding the low-density fractions of primed tomato and lettuce seeds improved the percentage of germination compared with nonprimed seeds. Physiological mechanisms are presented to explain the association of density with seed viability in lettuce (Lactuca sativa $\mathrm{L}$.).

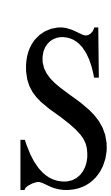

owing seeds, their subsequent germination, seedling emergence, and then establishment are primary events in crop production. Obtaining a uniform, vigorous plant stand is necessary for maximum yield potential and harvest efficiency. Stand establishment of a crop is influenced by the interaction of seed quality, seed-soil water relations, and growing-media environment.

Variousenvironmental stressesencountered after sowing may decrease or even prevent seedling establishment. For example, low temperatures combined with excess soil moisture may decrease the germination and subsequent establishment of large-seeded legumes. The influence of these detrimental environmental conditions on stand establishment becomes even more pronounced when the seeds are of suboptimal quality. Seed quality is a broad term that encompasses such aspects as the germination and vigor of a particular seed lot. Seed lots seldom have $100 \%$ germination, and therefore seedling emergence is limited first by the percent viability. Seed conditioning may be used to upgrade seed quality before sowing by eliminating nonviable or poor-quality seeds. Other limitations can be reduced by seed treatments and coatings for precision seed placement.

Water is essential for all life processes, and water status or seed moisture content plays a major role in the agronomic life cycle of seeds. Seed moisture is important during seed development and maturation while seeds are on the mother plant, harvesting, conditioning (Copeland and McDonald, 1985) and storage (Justice and Bass, 
1978; Priestley, 1986; Roberts, 1972, 1988). Finally, the water status of seeds and soils directly affects germination and stand establishment,

This article presents topics that deal with the role of water in seeds and the manipulation of waterstatus for improved germination and seedling emergence. The first section is devoted to the physiologicaldisorder, imbibitional chilling injury, with emphasis on the role of seed moisture content and seed coat characteristics in susceptibility to injury. Two approaches are presented to reduce the incidence of chilling injury. The first approach is based on the use of snap bean breeding lines that have seed coats with differential permeability to water, termed "semi-hard seeds." The second relies on seed coating technology to regulate water uptake during imbibition. This section briefly discusses priming as a presowing treatment that allows partial hydration followed by dehydration in a controlled environment, and also discusses seed conditioning at elevated seed moisture levels. The physical characteristic of seed density was explored as a means to improve seed quality. Mechanisms are presented that account for the association of hydrated seed density with seed quality in lettuce.

\section{Water Status of Seeds}

An understanding of classical water relations with respect to storage and germination is necessary for further discussion. Definitions and explanations of water relations in seeds are available in Koller and Hadas (1982) and Bewley and Black (1985). Through a fundamental understanding of water relations in seeds, appropriate technologies can be developed to improve stand establishment.

Water potential $(\Psi)$ is determined by the relative humidity of air at a particular temperature (Slatyer, 1967). The Kelvin equation can be used to calculate the $\Psi$ of air measured in MPa with a known relative humidity (Oosterhuis and Wullschleger, 1989):

$$
\Psi=\left(\mathrm{RTž}_{\mathrm{Z}} \mathrm{w}^{-1}\right) \operatorname{In}\left(\mathrm{eže}_{0}^{-1}\right),
$$

where $\mathrm{R}$ is the universal gas constant $(8.3143 \mathrm{x}$ $\left.10^{-6} \mathrm{~m}^{3} \mathrm{žMPažmol}^{l} \mathrm{~K}^{\mathrm{1}}\right)$, T is the absolute temperature $(\mathrm{K}), \mathrm{V}_{\mathrm{w}}$ is the partial molar volume of pure water $\left(1.805 \times 10^{-5} \mathrm{~m}^{3} / \mathrm{mol}^{-1}\right)$, and e and $\mathrm{e}_{0}$ are the partial and saturated vapor pressure of hater at temperature $\mathrm{T}$. The value eže $\mathrm{e}_{0}^{-1}$ gives the relative humidity of the air and is expressed as a fraction. This physical relationship can be used to describe the status of water in seeds at a given humidity and temperature.

Water activity and moisture isotherms. Water activity is the equivalent of the relative humidity of a material expressed as a decimal. Like relative humidity, water activity is related to water potential in a log-linear relationship. The activity refers to the availability of water in a material such as seeds (Rockland, 1969). Moisture content refers to the amount of water in seeds, and the water activity is related to moisture content in a nonlinear manner.

The moisture content of seeds comes into equilibrium with the relative humidity of air with time. The relationship between seed moisture content and relative humidity at a particular temperature reveals a negative sigmoidal curve and is known as a moisture isotherm (Iglesias and Chirife, 1982). This information is commonly generated by placing seeds over saturated salt solutions of known relative humidity under static conditions, Several references are available to prepare solutions with known humidity at a specific temperature (Carr and Harris, 1949; Rockland, 1960; Winston and Bates, 1960). Other procedures to obtain moisture isotherms have been reviewed (Iglesias and Chirife, 1982).

Moisture isotherms have been presented for a wide range of foods and food components, including seeds (Iglesias and Chirife, 1982). For example, the moisture isotherm for Phaseolus reveals a typical negative sigmoidal curve with three distinct zones: zone I occurs at low humidity $(<20 \%)$ zone II ranges from $\approx 25 \%-65 \%$, and zone Ill occurs at higher humidities $(>70 \%)$ (data not shown). Seed composition and temperature also influence moisture isotherms. Seeds with high-lipid content have a lower moisture content than low-lipid-content seeds at the same relative humidity and temperature. Less water is absorbed at high temperatures, and raising the temperature decreases the moisture content at a given humidity (Priestley, 1986).

The status of water-binding within the different zones has been discussed (Leopold and Vertucci, 1989; Priestley, 1986; Rockland, 1969). Water is bound tightly in zone I, and strong interactions exist between water molecules and the charged carboxyl and amino groups of proteins and other constituents. In zone II, water is bound less tightly than in zone I, and hydrogen bonding of water to the hydroxyl groups of starch and to the hydroxyls and amides of proteins predominates. Free or mobile water exists in zone III, in which capillary and osmotic forces hold water.

lmbibition and germination. Water uptake in seeds is the first step toward germination. Water is essential to change the status of seed development from quiescence to active growth. Water uptake of seeds is characterized by three phases (Bewley and Black, 1985; Koller and Hadas, 1982). The first phase, known as imbibition, is a physical process and occurs in both live and dead seeds. Assuming that there are no dormancy mechanisms present, i.e., impermeable seed coats, water movement into seeds is rapid and a large increase in seed moisturecontent results. Phase II is the lag phase of water uptake and occurs before the onset of visible germination (radicle emergence). Another large increase in water uptake is measured in phase III, and this phase is associated with visible germination that marks the transition from seed to seedling.
The seed's ability to withstand desiccation after hydration is related to the hydration phase. Seeds are desiccation-tolerant during phases I and II and become desiccation-intolerant upon entering phase III. Therefore, seed treatments that involve a short soaking period, partial hydration, or hydration-arrest before the completion of visible germination may be redried without injury. These relationships have practical significance for storage of once-hydrated seeds and allow sowing of these seeds with conventional planters.

The triphasic water uptake of seeds can be explained on the basis of water relations. Dry seeds may have a water potential less than -100 MPa (Hegarty, 1978). Thus, a large water potential gradient initially exists between the seed and highwater potential medium such as a moist soil, solution, or water. The rapid rate of water uptake measured in phase I occurs primarily due to the seed's matric potential $(\Psi \mathrm{m})$. In phase II, the $\Psi \mathrm{m}$ plays a minor role and the water potential of the seed is further regulated by the osmotic potential $(\Psi \mathrm{s})$ and pressure potential $(\Psi \mathrm{p})$ creating a static relationship between seed moisture and water uptake. Cell elongation (growth) occurs in phase III, and this growth results in additional water uptake by the seedlings. Mobilization of storage compounds in phase III results in the production of osmotically active compounds that further decrease $\Psi \mathrm{s}$ and increase water uptake.

The kinetics of water uptake during phases I and II have been studied in several species (Leopold, 1983). The dynamics of imbibition fit first-order reaction kinetics with respect to both weight and volume gain overtime. The rate of water uptake depends on the environment and the properties of the seed (Vertucci, 1989). The water potential differential between the environment and the seed establishes the gradient but not the rate of imbibition. The rate of imbibition is influenced by the permeability of the seed to water. Components that influence the hydration rate includeseed morphology, composition, moisture content, and temperature.

Imbibition is accompanied by gains in weight and volume. However, the percent increase in weight may not be the same as the percent increase in volume for a particular species under the same conditions of time, temperature, and osmoticum. For example, 15 seed types with a range of dry specific gravities of $\approx 0.85$ to 1.35 were imbibed, and a negative linear relationship ( $\mathrm{R}=-0.923)$ was determined between dry seed density and density after imbibition (Leopold, 1983). The percent increase in weight was not identical to the percent increase in volume. Watervolume does notdirectly displace its weight, because water affects the degree of swelling of seed polymers.

\section{Imbibitional Chilling Injury}

Chilling injury is a physiological disorder that occurs in warm-season crops that originate from tropical or subtropical regions (Lyons, 1973). 
Chilling injury in seeds generally is accompanied by elevated leakage rates that further stimulate soil pathogens; however, these topics are not discussed in this paper. The reader is referred to other review articles on chilling injury in seeds and seedlings for further discussion (Herner, 1986, 1990; Wolk and Herner, 1982).

Susceptibility to chilling injury depends on several factors, including the period of exposure to stress. There are two groups of chilling-sensitive seeds (Herner, 1986) The first is not injured during imbibition but is sensitive after radicle emergence. Crop seeds representative of this group are tomato (Lycopersicon esculentum Mill.) and watermelon (Citrullus lanatus [Thunb.] Matsum. \& Nakai). Seeds in the second group are injured during early phases of imbibition. Examples of this group include cotton (Gossypium hirsutum L.), corn (Zea mays L.), and warmseason, large-seeded legumes such as snap bean and soybean [Glycine $\max (\mathrm{L}$.) Merr.]. It is this second group that is of primary interest in this discussion.

Several factors influence the degree of imbibitional chilling injury for a particular species. Environmental factors include low soil temperature and high water availability. Seed factors include the initial seed moisture content and seed coat permeability. Seed-related factors will be studied in this paper with respect to imbibitional chilling injury.

The influence of initial seed moisturecontent on the incidence of chilling injury in large-seeded legumes has been documented in earlier reports. In lima bean (Phaseolus lunatus L.) (Pollock, 1969) and soybean (Obendorf and Hobbs, 1970) chilling is most severe when seeds of low initial moisture content are imbibed at low temperatures. Snap bean seeds with moisture contents $>12 \%$ (freshweight basis) had greater field emergence than lower-moisture seeds, and emergence differences were greatest due to seed moisture levels when the soil temperature was <10C (Roos and Manalo, 1976).

Initial seed moisture content critically influences the susceptibility of the seed to imbibitional chilling injury. The seed moisture content marking the onset of imbibitional chilling injury (break point) was determined at 20 and $5 \mathrm{C}$ on snap beans (Wolk et al., 1989). The seed moisture content breakpoints for 'Tendercrop', a chilling-sensitive cultivar, were 0.15 and $0.19 \mathrm{~g}$ water $/ \mathrm{g}$ dry weight at 20 and $5 \mathrm{C}$, respectively. Expressed on a freshweight basis (ASAE, 1987), these moisture contents are $13 \%$ and $16 \%$, respectively. The breakpoints for 'Kinghorn Wax', a more chilling-tolerant cultivar, were 0.11 and 0.16 gžg g $^{-1}$ at 20 and $5 \mathrm{C}$, respectively. The corresponding moisture contents for these temperatures are $9.9 \%$ and $13.8 \%$, respectively. Averaged over all treatments, a $4.6 \%$ reduction in germination was accompanied by a $0.01 \mathrm{gžg}^{-1}(1.0 \%)$ reduction in initial moisture content below the break point.
Role of testa end imbibition rate on chilling injury. The role of the seed coat has been studied in relation to imbibitional chilling injury (Tully et al., 1981). The imbibition rate of pea (Pisum sativum L.) seeds, a chilling-tolerant crop, was much slower than that of soybean. Nicking the pea seed coat, which allowed rapid imbibition, induced chilling injury symptoms. The rate of imbibition was greater for embryos than for intact seeds of pea, and cellular death was associated with rapid water uptake (Powell and Matthews, 1978). The same workers later proposed that the injury was caused by imbibition and not low temperatures and further demonstrated a relationship between the percent seed coat damage and hydration rate (Powell and Matthews, 1979). The effect of presence or absence of the testa on leakage of marker enzymes during imbibition of soybean, navy bean (P. vulgaris L.), pea, and peanut (Arachis hypogea L.) (Duke and Kakefuda, 1981) was studied. Seeds without testa were found to leak both cystolic and mitochondrial enzymes, whereas intact seeds only leaked cystolic enzymes. These data indicate that the testa prevented cellular rupture. It can be concluded collectively from these studies that the testa play a major role in regulating the imbibition rate, thusaffecting susceptibility to injury and subsequent germinability.

Imbibition rate can be regulated by the available water in the environment to the seeds. Soybean seeds were imbibed initially at $5 \mathrm{C}$, and the hydration rate was varied by altering water availability. Increased hydration rate resulted in a linear decrease in radicle length of soybean seedlings (Vertucci, 1989). Only a slight decline in radicle length was measured, as hydration rate increased if seeds were imbibed at 25C. Similar studies on snap beans revealed the same relationship, a decline in the percent germination with increased hydration rate (Wolk, 1988). Herner (1989) warned that the absolute rate of water uptake is not correlated with imbibitional injury. Both conditions of low initial moisture and low temperature decrease imbibition rate. Therefore, imbibition rate should be used only under the same conditions of initial moisture content and temperature and with the same species.

Seedling emergence forces and chilling injury. It is of practical and fundamental interest to study the influence of initial seedmoisture contentand imbibition temperatureon germination and seedling emergence force. Information can be used to assess the influence of imbibitional chilling injury on subsequent seedling emergence under soil-crusting conditions. Emergence forces could be related to the physiological mechanism of the injury process.

An apparatus was developed to quantify the forces generated from a collective group of seedlings (Taylor and Ten Broeck, 1988). Briefly, 50 seeds were sown in a flat containing pasteurized builders' sand. Seeds were oriented so that the radicles would emerge from the seed coat and grow straight downward. Hypocotyls of the germinating seedlings pushed against a plexiglass plate connected to a force transducer. Interfaced with a strain-gauge conditioner, a chart recorder monitored the force generated over time. In this manner, the performance of a representative sample of seeds could be determined that would reflect seed lot quality.

Seedling emergence forces have been measured for snap beans (Taylor, 1988). In this study, seeds of 'Bush Blue Lake 47' snap beans were sized to an average of $275 \mathrm{mg}$ and equilibrated to $8 \%$ or $12 \%$ moisture. These seeds were sown in flats with sand and then watered to $15 \%$ moisture. The flats were maintained at 5 or $25 \mathrm{C}$ for the first $24 \mathrm{~h}$, and then transferred to $25 \mathrm{C}$ until the hypocotyls emerged from the sand. The emergence force then was recorded with the apparatus described for a period of up to $72 \mathrm{~h}$. The percentage of seedlings emerged, time to reach maximum force, total force, and force per seedling were recorded.

Seedling emergence forces were influenced by the interaction of imbibition temperature and initial seed moisture content. Imbibing seeds with low moisture content (8\%) at $25 \mathrm{C}$ decreased the percent seedling emergence and total force compared with high moisture (12\%) seeds at the same temperature. Imbibing low-moisture seeds (8\%) at lowtemperatures decreased percentemergence, total force, and force per seedling and increased the time to achieve maximum force compared with the other treatments (Table 1). No differences were observed in any parameter from $12 \%$ moisture seeds at either temperature. Using the crosssectional areas of the hypocotyls, pressures of 165 and $250 \mathrm{kPa} /$ seedling were measured from seeds imbibed at $5 \mathrm{C}$ with $8 \%$ moisture and $25 \mathrm{C}$ with $12 \%$ moisture, respectively (data not shown).

Sowing low-moisture seeds in cold soil decreased percent seedling emergence. Therefore, one effect of imbibitional chilling is a reduction in the survival rate of seedlings. However, other effects also were observed. The surviving seedlings from chilled seeds required a longer period to achieve maximum force, and less force was generated per seedling (Table 1). Reduced performance from chilled seeds may be attributed to metabolic dysfunction. Respiration and seedling growth rates were decreased after chilling lima bean seeds (Woodstock and Pollock, 1965). Increased solute leakage, accompanied by imbibitional chilling injury (Bramlage et al., 1978) could deplete substrates for growth and ultimately decrease seedling emergence force. Several factors are apparently involved in decreasing emergence force of seedlings, even though the injury was sustained earlier in the germination process.

Semi-hard seeds. Seed coat permeability is an important factor in regulating imbibition rate and chilling injury. Dark-seeded snap bean lines imbibe more slowly than white-seeded lines due to greater seed coat weight and thickness (Wyatt, 
Table 1. Seedling emergence forces of snap beans influenced by initial seed moisture content and imbibition temperature?.

\begin{tabular}{|c|c|c|c|c|c|}
\hline $\begin{array}{l}\text { Seed } \\
\text { moisture } \\
\text { (\%) }\end{array}$ & $\begin{array}{c}\text { Imbibition } \\
\text { temp } \\
\left({ }^{\circ} \mathrm{C}\right) \\
\end{array}$ & $\begin{array}{c}\text { Seedling } \\
\text { emergence } \\
(\%)\end{array}$ & $\begin{array}{c}\text { Total } \\
\text { time } \\
(\mathrm{h}) \\
\end{array}$ & $\begin{array}{l}\text { Total } \\
\text { force } \\
(\mathrm{N})^{2}\end{array}$ & $\begin{array}{c}\begin{array}{c}\text { Force/ } \\
\text { seedling } \\
(\mathrm{N})\end{array} \\
\end{array}$ \\
\hline 8 & 25 & 83 & 49 & 126 & 3.0 \\
\hline 12 & 25 & 93 & 40 & 168 & 3.6 \\
\hline 8 & 5 & 67 & 65 & 79 & 2.4 \\
\hline 12 & 5 & 89 & 48 & 172 & 3.9 \\
\hline $\operatorname{LSD}^{\gamma}$ & & 8 & 14 & 30 & 0.6 \\
\hline
\end{tabular}

1977). Imbibition damage was observed in a whiteseeded bean cultivar at both 20 and $4 \mathrm{C}$, while the dark-seeded cultivar was only injured at $4 \mathrm{C}$ (Powell et al., 1986).

Hard-seededness may be a valuable characteristic for improvement of overall seed quality. Seed viability on the mother plant and after accelerated aging was maintained better in a hard-seeded soybean line than in a cultivar with permeable seed coat (Potts et al., 1978). However, seed size has been shown to influence the expression of the impermeable seed coat trait (Hill et al., 1986) smaller seeds exhibiting the impermeable response at a higher frequency than larger seeds.

A coat-imposed dormancy mechanism also would greatly decrease the imbibition rate. The semi-hard seed (SHS) characteristic has been selected in a snap bean breeding program (Dickson and Boettger, 1982). Semi-hard seeds are those seeds that do not imbibe water during a 24-h period when the initial seed moisture content is $6 \%$. Semi-hard seeds with 5\% to $10 \%$ moisture do not imbibe water completely in one day, and they hydrate readily when the moisture content is $>10 \%$ (Taylor and Dickson, 1987).

The nature of the semi-hard seed characteristic has been studied in snap beans (Holubowicz et al., 1988). It was demonstrated that water first enters the raphe and chalazal regions of the testa (R-CT) during imbibition. Semi-hard seeds contained more phenols in the osteosclereid cells and more pectic substances in the palisade cells of the CT than a cultivar with a permeable seed coat. Greater accumulation of these substances could account for the impermeable nature of the seed. Measurements of palisadecell lengthand width in the CT region revealed that cell length increased and "width decreased as seed moisture content increased from $6 \%$ to $12 \%$. It was proposed that the semi-hard trait is mainly due to the reversible physical nature of palisade cells. At low moisture contents, the palisade layer does not permit water to pass, since the cells are closely packed. The seeds hydrate readily at high moisture contents since the cells decrease in width, allowing the water to pass.

The susceptibility of SHS to chilling injury was studied by Taylor and Dickson (1987). Seed moisture content of two commercial cultivars-
'Bush Blue Lake 47' and 'Burly-and a breeding line with the SHS characteristic (NY 5345) were adjusted to $8 \%, 10 \%$, or $12 \%$ (fresh-weight basis). Hydration studies were performed by submerging seeds in water and determining water uptake over time. A chilled germination test was conducted by placing seeds in sand, prechilled and moistened to $22 \%$ (dry-weight basis). Seeds remained in the sand for $24 \mathrm{~h}$ maintained at $5 \mathrm{C}$, and then were transferred to roll towels maintained at $25 \mathrm{C}$. The percentage of germination was determined at the end of the test according to the Association of Official Seed Analysts (1981).

The sample of SHS with $8 \%$ moisture imbibed water slowly and required 6 days for full imbibition by the entire seed sample (Taylor and Dickson, 1987). Semi-hard seed with $12 \%$ initial moisture imbibed water readily, and no cultivar differences were observed in hydration rate. All cultivars with $12 \%$ moisture were tolerant to chilling injury. At $8 \%$ moisture, only SHS were not susceptible to chilling. Seedcoat permeability of SHS was readily reversible and was moderated by relative humidity of the storage environment.

Wolk (1988) showed that 'Kinghorn Wax' snap bean seeds exhibited the SHS characteristic and were more chilling-tolerant than the softseeded 'Tendercrop'. Greater chilling tolerance in 'Kinghorn Wax' also was attributed to the tight adherence of the testa to the embryo.

The influence of the semi-hard seed trait on plant performance was studied in laboratory and field trials. Plant breeding lines, obtained from M.H. Dickson, that exhibited various degrees of the SHS characteristic were evaluated. Four lines were selected for further study: NY5345, NY8741, NY8757, and NY8751. Seeds wereadjusted to $8 \%$ moisture content before all studies.

Imbibition profiles were determined by submerging seed samples in water and recording weight increases over time. The percent moisture content was calculated and plotted against time. A lag phase was observed, followed by a linear phase of water uptake. The moisture contents were transformed to natural logs (In) and replotted against time to reveal a linear relationship with hydration rate expressed as $\mathrm{K}$ :

$$
\mathrm{K}=\left(\left(\mathrm{In} M C-\operatorname{In} \mathrm{MC}_{0}\right) \mathrm{t}^{-1}\right)
$$

where $\mathrm{K}$ is the hydration rate, $\mathrm{MC}$ is the moisture content at time $\mathrm{t}, \mathrm{MC}_{0}$ is the initial moisture content, and $t$ is time in hours. The data from the first $12 \mathrm{~h}$ of imbibition were used to calculate $\mathrm{K}$ for NY5345, NY8741, and NY8757. The data from first $8 \mathrm{~h}$ were used to calculate $\mathrm{K}$ for NY 8751, since the hydration curve deviated from the linearity after 8 $\mathrm{h}$ due to the rapid hydration rate in this breeding line.

The percent warm and chilled germination were performed as described, and methods were taken from an earlier paper (Taylor and Dickson, 1987). Field experiments were established on 11 June 1987 and 3 June 1989 at the Vegetable Crops Research Farm, Geneva, N.Y., and seeds were treated with Captan at the recommended rate before sowing. Both studies were performed in warm soil conditions, and in 1987 the plots were irrigated after planting to achieve a wet soil condition.

The four breeding lines were selected to obtain a range of hydration rates. NY5345 was most impermeable, NY8757 and NY8741 were intermediate, and NY8751 was most permeable. All breeding lines had a $\mathrm{K}$ value $<0.24$, and for comparison the soft-seeded 'Bush Blue Lake 47' had a $\mathrm{K}$ value of 0.28 .

The relationships between seed hydration rates and plant performance are shown in Fig. 1. Mean separation was performed by LSD at $\mathrm{P}=0.05$. All lines had $>85 \%$ germination in the standard germination test. The most impermeable line had a reduction in germination compared with the other treatments. At the end of the test, NY5345 had $8 \%$ swollen seeds; these were not counted as normal seedlings. The chilled test revealed that the most permeable line was susceptible to imbibitional chilling injury. Injury was expressed by a greater percentage of abnormal seedlingsand dead seeds in this line than in the others. Field studies were performed to evaluate seedling establishment under wet (1987) and dry (1989) soil conditions. In 1987 a trend revealed that an increase in the hydration rate was accompanied by a decrease in field emergence $\left(\mathrm{r}=-0.98^{* *}\right)$. In 1989, large variation was measured in the study and few treatment differences were observed. However, the most impermeable line had the poorest emergence. This difference was due to the impermeable nature of the testa and not to chilling injury.

The reduced degree of permeability in breeding lines, reflected by a smaller $\mathrm{K}$ value, was accompanied by a longer lag period before water uptake. Hydration curves from individual SHS seeds have revealed that the time for imbibition to commence will vary over time, but that the kinetics of imbibition is similar from seed-to-seed after imbibition begins (Taylor and Prusinski, unpublished data). Therefore, the SHS trait delays the onset of imbibition rather than the absolute rate of hydration (Wolk, 1988)

These studies illustrate that the SHS characteristic is an important trait to consider for improvement of seed quality and plant performance. 

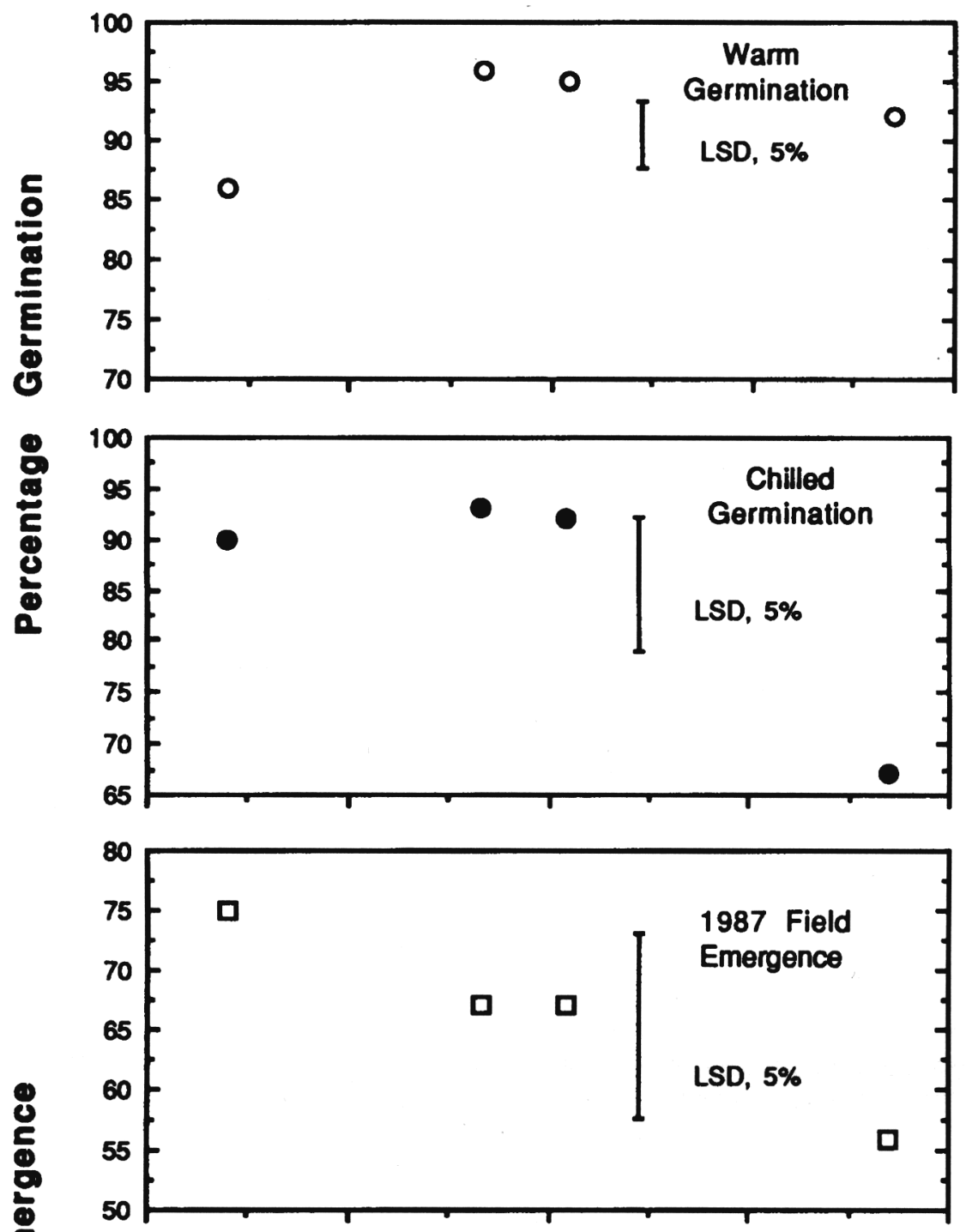

풀

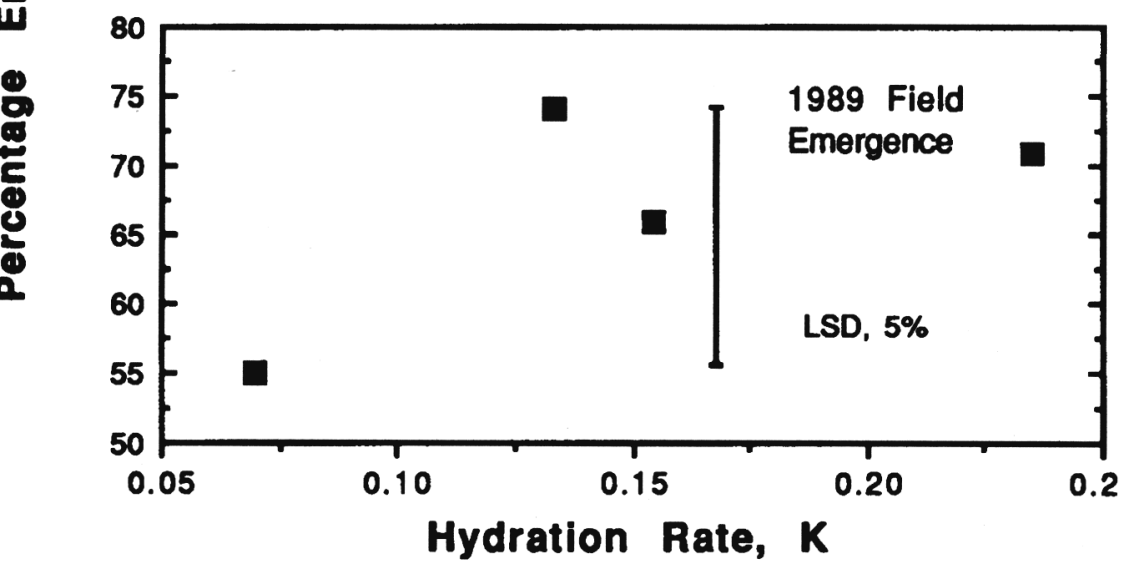

Fig. 1. Semi-hard seeds with $8 \%$ moisture content: hydration rates and the percent germination and percent field emergence.
However, selection of genetic material should be performed with caution. A high degree of impermeability can result in low standard germination results, since many seeds do not develop into normal seedlings by the end of the test. Field emergence may be lower under dry soil conditions due to coat-imposed dormancy. Lines with rapid hydration rates perform like permeable-seeded cultivars. These lines are susceptible to imbibitional chilling injury and perform poorly, especially under wet soil conditions. Breeding lines with intermediate SHS characteristics may perform best under a wide range of environmental conditions. These lines were not susceptible to chilling injury and were sufficiently permeable to allow normal germination in a short period.

Polymeric seed coatings. The imbibition or hydration rate already has been implied to be a major factor causing damage. The imbibition rate has been decreased by imbibing seeds in polyethylene glycol solutions (Powell et al., 1986; Tully et al., 1981). Interestingly, that imbibition rate was decreased in PEG, even though the initial water potential gradient between the seed and solution was extremely large. A reduction in imbibition rate 10 -fold greater than predicted was measured with PEG 8000 of known water potential (Vertucci, 1989) maybe due to the nature of PEG in solution. The water potential of large molecular weight PEG is regulated primarily by the matric forces of the ethylene oxide subunits of the polymer, and the osmotic potential had only a small contribution to the total water potential (Steuter et al., 1981). Thus, the term "matricum" rather than "osmoticum" may better describe PEG in solution. Viscosity of the PEG solutions also may have reduced the imbibition rate. Although imbibing of seeds in PEG solutions has been shown to reduce imbibition rates and susceptibility to chilling, this technique is not practical as a commercial seed treatment.

A seed technology approach to decrease seed coat permeability is to treat seeds with a material that retards imbibition. The addition of hydrophobic substances to seed pellets has improved germination of lettuce under wet soil conditions (Sooter and Millier, 1978). PEG has been incorporated into table beet (Beta vulgaris L.) seed pellets to improve seedling establishment under wet soil conditions (Khan and Taylor, 1986). However, pelleting large-seeded legumes such as snap beans is not practical. Seed-coating is less time-consuming, less expensive, and may be performed on a continuous basis.

Polymer coatings may serve to regulate imbibition rates. Soybean, cotton, and corn seeds were coated with lanolin to alleviate imbibitional chilling injury (Priestley and Leopold, 1986). Seeds first were cooled to 2 to $4 \mathrm{C}$, and a mixture of lanolin in acetone heated to $55 \mathrm{C}$ was poured onto the cold seeds. The lanolin was applied at a rate of 20 to 30 gžkg $^{-1}$ seed. The coating decreased imbibition rates, especially at low temperatures. Coated and 
noncoated seeds were sown in flats maintained at $2 \mathrm{C}$ for $18 \mathrm{~h}$ and then transferred to a greenhouse for 2 weeks. The percentage of seedling emergence and seedling fresh weight were recorded. In soybeans, the coating treatment improved both the percentage of emergence and seedling fresh weight. Only percentage of emergence was increased from coated cotton seeds, and no improvements were measured for corn.

Research was performed on developing a hydrophobic seed coating to alleviate chilling injury (Taylor, 1987). Proprietary polymers in an aqueous carrier were obtained (Gustafson, Inc.) and were applied on 'Bush Blue Lake 47' snap bean seeds in a tumbling drum apparatus. Heating or cooling the seeds or the solution was not necessary for the coating process. A small quantity of sand added during tumbling reduced agglomeration of seeds. Seed moisture content was adjusted to $8 \%$ or $12 \%$ before chilling. Seeds with $8 \%$ moisture had poor germination after being exposed to chilling (Taylor, 1987). Polymer coatings slightly improved chilled germination compared with the noncoated seed when both treatments were adjusted to $8 \%$ initial moisture content. However, no treatment with $8 \%$ moisture performed as well as control seeds with $12 \%$ moisture. Further improvements in coating technology for seeds were deemed necessary to decrease chilling injury.

Polymeric seed coatings were evaluated further on snap bean seed quality and seedling establishment. Six different proprietary coatings were applied to 'BBL-47' by Royal Sluis Holland, and a noncoated check was included for comparison. Seed moisture content of samples was adjusted to $8 \%$ or $12 \%$ before laboratory and field studies. Methods conducted for the warm, chilled, and field studies were described in the SHS section. The hydration rates were calculated during the first $2 \mathrm{~h}$ of imbibition and expressed as the percent change (increase) in moisture content per hour. Field studies were conducted on 12 May 1988 and 3 June 1989, and seeds were treated with Captan at the recommended rate before sowing. In 1988 plots were irrigated after planting to establish a wet soil condition. Field studies in 1989 were established concurrently with SHS experiments described earlier.

The hydration rates and laboratory and field performance from the seven treatments for $8 \%$ moisture-content seeds are shown in Table 2. The coatings influenced imbibition, giving decreases in water uptake ranging from slight to severe. No treatment differences were observed in the standard germination test; however, several coatings improved the percentage of germination in the chilled test. Coatings 5 and 6 performed more poorly than the nontreated control in the same study. All coated treatments performed better than the noncoated control in the 1988 field studies, and a negative correlation wasmeasured between field emergence and $\triangle \mathrm{MC}$ per hour. The slope of this relationship shows that a reduction in the hydration rate of $1 \%$ moisture/h resulted in a $3.5 \%$ increase in field emergence. No treatment differences were measured in 1989.

This study was performed with seeds equilibrated to $12 \%$ moisture content (Table 3). The hydration rates for seeds with $12 \%$ moisture content were greater than corresponding rates from $8 \%$ seeds (Table 2 vs. 3 ). Seed coatings influenced hydration rates and ranged from a slight increase to a substantial decrease compared with the noncoated treatment. Seeds from four of the six coatings had greater warm germination than the control. Hydration rates were correlated negatively with chilled germination results, and improvements in field emergence were recorded in 1988. No significant trends were observed between 1989 field results and hydration rates.

In general, several seed coatings retarded imbibition rates and improved seedling performance, especially understressful conditions. Seed coating 2 had the lowest hydration rate and performed best overall in laboratory and field trials. No detrimental effects of the coatings were measured under the dry soil conditions of 1989 such as those measured with the most impermeable SHS line (Fig. 1).
The initial wetting reaction has been suggested to be the primary causal factor of imbibitional chilling injury (Vertucci and Leopold, 1983). Treatments that retard the imbibition rate should alleviate the detrimental effects of rapid wetting on germination. Our studies illustrate that coatings can decrease hydration rates and subsequently improve seedling performance (Tables 2 and 3). Chilling injury is most severe in low-moisture seeds, and increasing moisture content before sowingcan improve seedling establishment (Table 2 vs. 3). Therefore, greater improvements in plant performance would be expected with coatings on seeds with $8 \%$ rather than $12 \%$ moisture. A $1 \%$ decrease in hydration rate $(\Delta \mathrm{MC} / \mathrm{h})$ was accompanied by $2.8 \%$ and $1.0 \%$ increase in chilled germination with $8 \%$ and $12 \%$ moisture seeds, respectively (Tables 2 and 3 ). In conclusion, polymeric coatings retarded imbibition rates and benefited seedling performance under wet soil conditions when the initial moisture content was low $(8 \%)$ or high $(12 \%)$ but the largest improvements were with low moisture-content seeds.

Several factors may decrease the success of a polymeric film coating. First, the polymer must uniformly cover the entire seed surface. Scanning

Table 2. The effect of seed coatings on snap bean seeds with $8 \%$ moisture content.

\begin{tabular}{|c|c|c|c|c|c|}
\hline \multirow[b]{2}{*}{ Treatment } & \multirow[b]{2}{*}{$\Delta M C / h$} & \multicolumn{2}{|c|}{ Germination (\%) } & \multicolumn{2}{|c|}{ Field emergence (\%) } \\
\hline & & Warm & Chilled & 1988 & 1989 \\
\hline Control & 13.3 & 82 & 44 & 52 & 55 \\
\hline Coating 1 & 12.2 & 91 & 46 & 64 & 60 \\
\hline Coating 2 & 7.4 & 92 & 68 & 80 & 55 \\
\hline Coating 3 & 8.0 & 90 & 51 & 69 & 55 \\
\hline Coating 4 & 9.1 & 86 & 57 & 66 & 58 \\
\hline Coating 5 & 8.8 & 85 & 42 & 69 & 61 \\
\hline Coating 6 & 10.8 & 85 & 41 & 62 & 59 \\
\hline $\operatorname{LSD}^{2}$ & 4.4 & NS & 13.8 & 9.5 & NS \\
\hline \multicolumn{2}{|c|}{ Correlation coefficient ${ }^{2}, r$} & -0.50 & -0.63 & $-0.89^{* \star}$ & 0.33 \\
\hline \multicolumn{2}{|c|}{ Slopey, m } & -0.85 & -2.8 & -3.5 & 0.40 \\
\hline
\end{tabular}

Mean separation within columns by $L S D, P=0.05$

Correlation coefficient and slope from relationship between $\Delta M C / h$ vs. germination or emergence.

Table 3. The effect of seed coatings on snap bean seeds with $12 \%$ moisture content.

\begin{tabular}{|c|c|c|c|c|c|}
\hline \multirow[b]{2}{*}{ Treatment } & \multirow[b]{2}{*}{$\Delta \mathrm{MC} / \mathrm{h}$} & \multicolumn{2}{|c|}{ Germination (\%) } & \multicolumn{2}{|c|}{ Field emergence (\%) } \\
\hline & & $\begin{array}{l}\text { Warm } \\
\end{array}$ & Chilled & 1988 & 1989 \\
\hline Control & 18.6 & 87 & 87 & 75 & 53 \\
\hline Coating 1 & 19.1 & 88 & 87 & 77 & 67 \\
\hline Coating 2 & 12.9 & 91 & 91 & 90 & 58 \\
\hline Coating 3 & 13.7 & 95 & 92 & 88 & 55 \\
\hline Coating 4 & 15.1 & 97 & 89 & 74 & 62 \\
\hline Coating 5 & 16.3 & 90 & 90 & 84 & 63 \\
\hline Coating 6 & 18.1 & 92 & 83 & 84 & 64 \\
\hline $\operatorname{LSD}^{2}$ & 2.4 & 6.9 & 6.9 & 10.8 & 9.4 \\
\hline Correlation coefficient ${ }^{2}, r$ & & -0.63 & $-0.80^{*}$ & -0.64 & 0.38 \\
\hline Slope ${ }^{y}, m$ & & -0.92 & -1.0 & -1.7 & 0.78 \\
\hline
\end{tabular}


electron microscopy revealed that a polymer studied earlier was not evenly deposited over and around the hilum (Taylor, 1987). Thus, the uncoated portion of the seed surface could still imbibe readily, resulting in uneven hydration through the seed tissue. The second factor depends on the polymer characteristics. The film should retard water diffusion but not totally prevent water movement. Finally, the coating must not be toxic or inhibitory to germination and seedling growth. The ideal coating would provide a nonharmful film completely around the seeds and be slightly hydrophobic in nature to retard imbibition.

Physiological seed treatments. Treatments that include seed hydration under controlled conditions before sowing have attracted considerable interest in the past two decades. Two techniques have been studied to improve the rate of germination-fluid drilling and seed priming. The methodology employed in fluid drilling or gel seeding and some early results have been reviewed by Gray (1981). Taylor and Harman (1990) reviewed the integration of fluid drilling with other selected seed treatments to further enhance plant performance.

Seed priming and osmoconditioning are terms describing a presowing hydration treatment using solutions of known water potential to improve seedling establishment. This topic has been reviewed by Heydecker and Coolbear (1977) Khan et al. (1980/81), and Bradford (1986). Integration of biological seed treatments with priming, including priming with solid matrix systems, has been reviewed by Taylor and Harman (1990).

The primary advantage of these presowing techniques has been improved germination rate. In general, little improvement in the percentage of total germination has been observed with these methods under ideal environmental conditions. However, these physiological seed treatments allow access to seeds after they are imbibed. Therefore, differences that are associated with seed quality may be revealed only in the hydrated state. Appropriate technologies then could be used to separate viable from nonviable seeds and effectively upgrade seed quality.

\section{Density Relationships of Hydrated Seeds}

It has been observed that seeds that have completed germination (radicle emergence) have a lower density than hydrated seeds without visible germination. This observation led to the development of a technique for separation of germinated from nongerminated seeds based on density differences (Taylor et al., 1978). Celery (Apium graveolens $\mathrm{L}$.) and pepper (Capsicum annuum $\mathrm{L}$.) seeds were germinated in aerated water until radicles emerged. The seeds then were separated into density fractions with sucrose solutions; the floating, top fraction contained the highest percentage of germinated seeds and the lower, denser fraction largely contained nongerminated seeds (Taylor et al., 1978). Further research has shown this technique to be effective for upgrading the quality of germinated seed in cabbage (Taylor and Kenny, 1985). A maltodextrin solution, replacing sucrose, was used to achieve known solution densities. The technique waseffective in removing nonviable seeds from aged and non-aged cabbage seeds. Solution density was investigated on percent germinated seed and loss (recovery) of germinated seed. In general, as solution density decreased the percent germinated seed in the floating fraction increased, while a greater percentage of germinated seeds sank and were therefore lost.

One disadvantage of this procedure was that seeds entered phase III, and this required that they be sown shortly after separation to avoid loss of viability and further decrease of radicle growth. Since radicles had emerged, a fluid system of sowing was required to facilitate sowing.

The principle of density separation of germinated seeds has been studied further to upgrade Brassica seed quality. In a series of papers, FinchSavage and coworkers (Finch-Savage, 1988; Finch-Savage and McKee, 1988, 1989; FinchSavage and McQuistan, 1988) developed procedures to dehydrate and store the separated germinated seeds termed low-moisture-contentgerminated (LMCG) seeds. Drying conditions were optimized to reduce moisture content of the newly germinated seeds without loss of viability. Germinated seeds first were surface-dried, thenfurther dried in an airstream between 20 and 30C with $80 \%$ relative humidity at 0.25 mžs $^{-1}$. Germinating rape (Brassica napus L.) seeds were stored successfully for 84 days at $-20 \mathrm{C}$, while storage life was only 7 days for LMCG seeds at $15 \mathrm{C}$. The exact environmental conditions required for safe drying and the relatively short storage life reveal that the germinated seeds were on the threshold of desiccation intolerance.

An alternate approach is to exploit density differences associated with seed quality before radicle emergence, while seeds are imbibed or primed. Seeds of lettuce, tomato, onion (Allium cepa L.), cabbage (B. oleracea var. capitata L.) and carrot (Daucus carota L.) were either imbibed in water or primed in PEG solutions (Hill et al., 1989). Seeds were separated into density classes of 0.02 $\mathrm{gžcm}^{-3}$ increments. Lettuce, tomato, and onion seed densities were related positively to percent germination. Other seed quality parameters including the rate and uniformity of germination and shoot length were generally improved as density increased.

The effect of priming or priming combined with the density-separation technique was compared with growth parameters of nontreated seeds of tomato and lettuce. Procedures used in this study have been described previously, and data on density separation were obtained from Hill et al. (1989). In this study, the low-density primed seeds were discarded in the separated primed treatment. Results were similar for tomato and lettuce for the parameters studied, and findings can be generalized for both crops. Percentage of germination was greater for the separated primed seeds than the nontreated seeds (Tables 4 and 5). Improvements in T50 were attributed to priming with or without separation. Uniformity of germination as measured by T10-90 was either unaffected or poorer for primed than for nonprimed seeds. Hypocotyl shoot lengths were greater from separated primed than from nontreated seeds.

This work demonstrated that improvements in seed quality can be obtained by conditioning seeds in the hydrated state. Physical characteristics such as density can be exploited to upgrade seed quality with a relatively small loss of good seed in the process. A float-sink process can be used to perform separations in a relatively short period. This procedure can be used to complement conventional priming techniques to further improve seed performance.

\section{Mechanisms Associated with Hydrated Lettuce Seed Quality and Density}

Physical characteristics of hydrated lettuce seeds have been studied in relation to endosperm integrity and leakage (Hill and Taylor, 1989). A brief discussion of lettuce seed morphology and leakage is necessary to understand the proposed mechanism. The lettuce embryo is surrounded by a two-cell-layer-thick endosperm enclosed by the outer maternal tissue that includes remnants of the integumentand pericarp (Borthwick and Robbins, 1928; Jones, 1974). The tissue of importance is the specialized endosperm that acts as a semipermeable membrane with a molecular exclusion limit of $\approx 300$ (Speer and Hsiao, 1976). The endosperm also has been shown to prevent leakage of potassium from seeds (Weges and Karssen, 1990). The endosperm would therefore allow free movement of water from the environment to the embryo, but reduce or prevent leakage of solutes. The extra-embryonic fluids were shown to contain proteins and carbohydrates; sucrose and ribose were the major compounds detected (Speer and Hsiao, 1976).

Leakage of compounds from seeds to the environment occurs during imbibition and has been documented in many species (Powell, 1986; Simon and Mills, 1983). In general, leakage is greater from nonviable or deteriorated seeds than from high quality seeds. This differential leakage has been attributed to lack of compartmentalization of cellular constituents, caused by faulty membranes or cellular rupture.

Nonviable lettuceseeds have been shown to have a greater weight and volume increase during imbibition than viable seeds (Hill and Taylor, 1989). Nonviableseeds imbibed $23 \%$ and swelled $26 \%$ more than viable seeds after an 8 -h soak. This 
Table 4. The percent germination, T50, T10-90, and shoot length of nontreated, primed, and separated primed tomato seeds.

\begin{tabular}{|lcccc|}
\hline Parameter & $\begin{array}{c}\text { Nontreated } \\
(\%)\end{array}$ & $\begin{array}{c}\text { Primed } \\
(\%)\end{array}$ & $\begin{array}{c}\text { Separated } \\
\text { primed } \\
(\%)\end{array}$ & LSD $^{\mathbf{y}}$ \\
\hline Germination (\%) & 88 & 92 & 96 & 4.7 \\
T50 (h) & 59 & 34 & 32 & 4.2 \\
T10-90 (h) & 23 & 30 & 28 & 7.0 \\
Shoot length (mm) & 19 & 27 & 27 & 1.9 \\
\hline
\end{tabular}

2The $\leq 1.08 \mathrm{~g} \mathrm{~cm}^{-3}$ density class was eliminated that contained $9 \%$ of the seeds.

yMean separation within rows by $L S D, P=0.05$.

Table 5. The percent germination, T50, T10-90, and shoot length of nontreated, primed, and separated primed lettuce seeds.

\begin{tabular}{|c|c|c|c|c|}
\hline Parameter & $\begin{array}{c}\text { Nontreated } \\
(\%)\end{array}$ & $\begin{array}{c}\text { Primed } \\
(\%)\end{array}$ & $\begin{array}{c}\text { Separated } \\
\text { primed }^{2} \\
(\%)\end{array}$ & $\operatorname{LSD}^{y}$ \\
\hline Germination (\%) & 87 & 90 & 94 & 4.4 \\
\hline T50 (h) & 33 & 14 & 13 & 3.6 \\
\hline T10-90 (h) & 19 & 24 & 22 & 6.8 \\
\hline Shoot length (mm) & 25 & 27 & 29 & 2.5 \\
\hline
\end{tabular}

The $1.04 \mathrm{gžcm}$ density class was eliminated that contained $5 \%$ of the seeds.

Mean separation within rows by $L S D, P=0.05$.

\section{VIABLE SEED}

\section{NONVIABLE SEED}

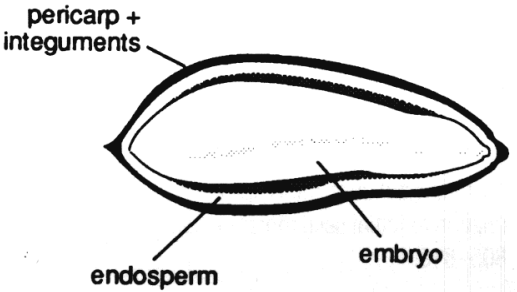

High Density

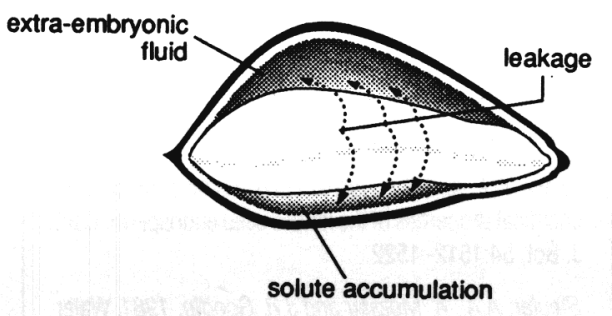

Low Density

Fig. 2. Mechanism governing the relationship between hydrated seed viability and density. Fig. 2. Mechanism governing the relationship between hydrated seed viability and density.

resulted in a lower density of nonviable than viable seeds. No differences in leakage, as measured by the electrical conductivity of the steep water, were measured between viable and nonviable seeds with intact endosperm. Puncturing the endosperm increased leakage and density of nonviable seeds compared with nonviable seeds with intact endosperms.

It is proposed that the relationship between physical characteristicsand seed viability is mediated by water relations (Fig. 2). Nonviable embryos leak more solutes than viable embryos. An intact endosperm, the typical condition for seeds, restricts leakage of solutes from the embryo to the environment, and, therefore, osmotically active molecules accumulate in theextra-embryonicfluid in nonviable seeds. This increased leakage creates a water potential gradient between the soak water and the seed resulting in increased water uptake. The additional water uptake by nonviable seeds increases seed swelling and results in a decrease in seed density relative to viable seeds.

\section{Literature Cited}

American Society of Agricultural Engineers. 1987 ASAE standards 1987. Amer. Soc. Agr. Eng., St. Joseph, Mich.

Association of Official Seed Analysts. 1981. Rules for testing seeds. J. Seed Technol. 6:1-125.

Bewley, J.D. and M. Black. 1985. Seeds: Physiology of development and germination. Plenum Press, N.Y.

Borthwick, H.A. and W. W. Robbins. 1928. Lettuce seed and its germination. Hilgardia 3:275-305.

Bradford, K.J. 1986. Manipulation of seed water relations via osmotic priming to improve germination under stress conditions. HortScience 21:1105-1112.

Bramlage, W. J., A.C. Leopold, and D. J. Parrish. 1978. Chilling stress to soybeans during imbibition. Plant Physiol 61:525-529.
Carr, D.S. and B.L. Harris. 1949. Solutions for maintaining constant relative humidity. Indust. Eng. Chem. 4:2014-2015

Copeland, L.O. and M.B. McDonald. 1985. Principles of seed science and technology Burgess. Minneapolis, Minn.

Dickson, M.D. and M.A. Boettger. 1982. Heritability of semi-hard seed induced by low seed moisture in beans (Phaseolus vulgaris L.). J. Amer. Soc. Hort. Sci. 107:69-71.

Duke, S.H. and G. Kakefuda. 1987. Role of the testa in preventing cellular rupture during imbibition of legume seeds. Plant Physiol. 67:449-456.

Finch-Savage, W.E. 1988. A comparison of brussels sprout seedling establishment from natural and lowmoisture-content germinated seeds. Ann. Applied Biol. $113: 425-429$

Finch-Savage, W.E. and J.M.T. McKee. 1988. A study of the optimum drying conditions for cabbage seed following selection on the basis of a newly-emerged radicle. Ann. Applied Biol. 113: 415-424.

Finch-Savage, W.E. and J.M.T. McKee. 1989. Viability of rape (Brassica napus L.) seeds following selection on the basis of newly-emerged radicles on subsequent drying and storage. Ann. Applied Biol. 114: 567-595.

Finch-Savage, WE. and C.I. McQuistan. 1988. The potential for newly-germinating cabbage seed survival and storage at sub-zero temperatures. Ann. Bot. 62:509512.

Gray, D. 1981. Fluid drilling of vegetable seeds. Hort. Rev. 3:1-27.

Hegarty, T.W. 1978. The physiology of seed hydration and dehydration, and the relation between water stress and the control of germination: a review. Plant Cell \& Environ 1:101-119.

Herner, R.C. 1986. Germination under cold soil conditions. HortScience 21:1118-1122.

Herner, R.C. 1990. The effects of chilling temperatures during seed germination and early seedling growth. $p$. 51-70. In: C.Y. Wang (ed.). Chilling injury of horticultural crops. CRC, Boca Raton, Fla.

Heydecker, W. and P. Coolbear. 1977. Seed treatments for improved performance-survey and attempted prognosis. Seed Sci. \& Technol. 5:353-425.

Hill, H.J. and A.G. Taylor. 1989. Relationship between viability, endosperm integrity and imbibed lettuce seed density and leakage. HortScience 24:814-816.

Hill, H.J., A.G. Taylor, and T.G. Min. 1989. Density separation of imbibed and primed vegetable seeds. J. Amer. Soc. Hort. Sci. 114:661-665.

Hill, H. J., S. H. West, and K. Hinson. 1986. Soybean seed size influences expression of the impermeable seed-coat trait. Crop Sci. 26:634-637.

Holubowicz, R., A.G. Taylor, M.C. Goffinet, and M.H. Dickson. 1988. Nature of the semihard seed characteristic in snap beans. J. Amer. Soc. Hort. Soc. 113:248-252.

Iglesias, H.A. and J. Chirife. 1982. Handbook of food isotherms: Water sorption parameters for food and food components. Academic, New York.

Jones, R.L. 1974. The structure of the lettuce endosperm. Planta 121:133-146. 
Justice, O.L. and L.N. Bass. 1978 Principles and practices of seed storage. Agr. Hdbk. 506, USDA, Washington, DC.

Khan, A.A., N. H. Peck, and C. Samimy. 1980-81. Seed osmoconditioning: Physiological and biochemical changes. Israel J. Bot. 29:133-144.

Khan, A.A. and A.G. Taylor. 1986. Polyethylene glycol incorporation in table beet seed pellets to improve emergence and yield in wet soil. HortScience 21:987-969.

Koller, D. and A. Hadas. 1982. Water relations in the germination of seeds, p. 401-431. In: D.L. Lange, P.S. Nobel, C.B. Osmond, and H. Ziegler (eds.). Encyclopedia of plant physiology. New Ser. vol. 12B. Springer-Verlag, Berlin.

Leopold, A.C. 1983. Volumetric components of seed imbibition. Plant Physiol. 73:677-680.

Leopold, A.C. and C.W. Vertucci. 1989. Moisture as a regulator of physiological reaction in seeds, p. 51-68. In: P.C. Stanwood and M.B. McDonald (ed.). Seed moisture. CSSA Spec. Pub. 14.

Lyons, J.M. 1973. Chilling injury in plants, Annu. Rev. Plant Physiol. 24:445-466.

Obendorf, R.L. and P.R. Hobbs. 1970. Effect of seed moisture on temperature sensitivity during imbibition of soybean. Crop Sci. 10:563-566

Oosterhuis, D. M. and S.D. Wullschleger. 1989. Psychrometric water potential analysis in leaf discs, p. 113133. In: H.F. Linskens and J.F. Jackson (ed.). Modern methods of plant analysis. Gases in plant and microbial cells. New Ser. vol. 9, Springer-Verlag, Berlin,

Pollock, B.M. 1969. Imbibition temperature sensitivity of lima bean seeds controlled by initial seed moisture. Plant Physiol. 44:907-911,

Potts, H.C., J. Duangpatra, W.G. Hairston, and J.C. Delouche. 1978. Some influences of hardseededness on soybean seed quality. Crop Sci. 18:221-224.

Powell, A.A. 1986. Cell membranes and seed leachate conductivity in relation to the quality of seed for sowing. J. Seed Technol. 10:81-100.

Powell, A.A. and S. Matthews. 1978. The damaging effect of water on dry pea embryos during imbibition. J. Expt. Bot., 29:1215-1229.

Powell, A.A. and S. Matthews. 1979. The influence of testa condition on the imbibition and vigour of pea seeds. J. Expt. Bot. 30:193-197.
Powell, A.A., M. de A. Oliveira, and S. Matthews. 1986, The role of imbibition damage in determining the vigour of white and coloured seed lots of dwarf French beans (Phaseolus vulgaris). J. Expt. Bot. 37:716-722.

Priestley, D.A. 1986. Seed aging: Implications for seed storage and persistence in the soil. Cornell Univ. Press, Ithaca, N.Y.

Priestley, D.A. and A.C. Leopold. 1986. Alleviation of imbibitional chilling injury by use of lanolin. Crop Science 26:1252-1254

Roberts, E.H. 1972. Viability of seeds. Syracuse Univ. Press, Syracuse, N.Y.

Roberts, E.H. 1988. Seed aging: the genome and its expression, p. 466-498. In: L.D. Nooden and AC. Leopold (eds.). Senescence and aging in plants. Academic, 'London.

Rockland, L.B. 1960. Saturated salt solutions for static control of relative humidities between $5^{\circ}$ and $40^{\circ} \mathrm{C}$. Anal. Chem. 32:1375-1376.

Rockland L.B. 1969. Water activity and storage stability. Food Technol. 23:1241-1251.

Roos, E.E. and J.R. Manalo. 1976. Effect of initial seed moisture on snap bean emergence from cold soil. J. Amer. Soc. Hort. Sci. 101:321-324.

Simon, E.W and L.K. Mills 1983. Imbibition, leakage and membranes. Recent Adv. Phytochem. 17:9-27.

Slatyer R.O. 1967. Plant-water relationships. Academic, London.

Sooter, C.A. and W.F. Millier. 1978. The effect of pellet coatings on the seedling emergence form lettuce seeds. Trans. Amer. Soc. Agr. Eng. 21:1034-1039.

Speer, H.L. and A.I. Hsiao. 1976. Some physical and chemical properties of the lettuce seed endosperm. Can. J. Bot. 54:1512-1522.

Steuter, A.A., A. Mozafar and J. R. Goodin. 1981. Water potential of aqueous polyethylene glycol. Plant Physiol. 67:64-67.

Taylor, A.G. 1987. Seed coatings to reduce imbibitional chilling injury. Ann. Rpt. Bean Imp. Coop. 30:30-31.

Taylor, A.G. 1988. Emergence forces of snap bean seedlings. Ann. Rpt. Bean Imp. Coop. 31:162-163.

Taylor, A.G. and M.H. Dickson. 1987. Seed coat permeability in semi-hard snap bean seeds: Its influence on imbibitional chilling injury. J. Hort. Sci. 62:183189.
Taylor, A.G. and G.E. Harman. 1990. Concepts and technologies of selected seed treatments. Ann. Rev. Phytopathol. 28:321-339.

Taylor, A.G., and T.J. Kenny. 1985. Improvement of germinated seed quality by density separation. J. Amer. Soc. Hort. Sci. 110:347-349.

Taylor, A.G., J.E. Motes, and H.C. Price. 1978. Separating germinated from ungerminated seed by specific gravity. HortScience 13:481-482

Taylor, A.G. and C.W. Ten Broeck. 1988. Seedling emergence forces of vegetable crops. HortScience 23:367-369.

Tully, R. E., M.E. Musgrave, and A.C. Leopold. 1981. The seed coat as a control of imbibitional chilling injury. Crop Sci. 21:312-317.

Vertucci, C.W. and A.C. Leopold. 1983. Dynamics of imbibition by soybean embryos. Plant Physiol. 72:190193.

Vertucci, C. W. 1989. The kinetics of seed imbibition: Controlling factors and relevance to seedling vigor. $p$. 93-115. In: P.C. Stanwood and M.B. McDonald (eds.) Seed moisture. CSSA Spec. Pub. No. 14.

Weges, R. and C.M. Karssen. 1990. The influence of redesiccation on dormancy and $\mathrm{K}^{+}$leakage of primed lettuce seeds. Isr. J. Bot. 39:327-336.

Winston, P.W. and D. H. Bates. 1960. Saturated solutions for the control of humidity in biological research. Ecology 41:232-237.

Wolk, W.D. 1988. Imbibitional injury of Phaseolus vulgaris $L$. seeds. PhD Diss., Michigan State Univ.

Wolk, W.D., P.F. Dillon, L.F. Copeland, and D.R. Dilley. 1989. Dynamics of imbibition in Phaseolus vulgaris $L$. in relation to initial seed moisture content. Plant Phys. 89: 805-810.

Wolk, W.D. and R.C. Herner. 1982. Chilling injury of germinating seeds and seedlings. HortScience 17:169173.

Woodstock, L.W. and B.M. Pollock. 1965. Physiological predetermination: Imbibition, respiration and growth of lima bean seeds. Science 150:1031-1032.

Wyatt, J.E 1977 Seed coat and water absorption properties of seed of near-isogenic snap bean lines differing in seed coat color. J. Amer. Soc. Hort. Sci. 102:478-480. 